\title{
EL ARTE DE AMAR: \\ UN ANÁLISIS SOCIOLÓGICO
}

\section{Concepción Fernández Villanueva}

Universidad Complutense de Madrid

E-mail: sosocio@sis.ucm.es

\begin{abstract}
RESUMEN
El trabajo presenta un análisis sociológico sobre el concepto de amor y las estrategias y técnicas del cortejo amoroso en cuatro autores clásicos: el Kama Sutra, el Arte de amar, El collar de la paloma y el Libro de buen amor. El concepto de amor mantiene un contenido común a lo largo de las diferentes épocas históricas que consiste en un sentimiento sublime de matiz positivo que transforma las relaciones sociales, así como la personalidad de los amantes. Las estrategias amorosas, por el contrario, se mantienen dentro de las leyes de la estructura social, manifestando las constantes de desigualdad en relación a los sexos, las clases sociales y los estereotipos propios de los valores y culturas en que vivieron sus autores.
\end{abstract}

\section{ARTE, CIENCIA Y MALAS ARTES: \\ LAS CONTRADICTORIAS DEFINICIONES DEL AMOR}

Introducir una reflexión sobre el arte de amar significa reconocer que el amor es un arte. Pero ¿qué es el amor? El concepto de amor pertenece al discurso de la vida cotidiana y, por ello, todo el mundo parece saber en qué consiste o parece haberlo experimentado. La pertenencia al discurso cotidiano del concepto de amor hace difícil definirlo desde parámetros académicos o científicos. Su contenido parece crearse y diluirse en ese mismo discurso de la vida cotidiana en el que, junto al manejo continuo de la palabra, se mantiene la

\section{Reis}


idea de que el amor es algo ilusorio, del que nadie sabe nada porque, verdaderamente, no existe.

En el transcurso de la historia del conocimiento podemos decir que el amor ha pasado de ser un arte a ser un sentimiento diseccionado por la ciencia. La concepción del amor como arte es antigua. Pertenece a autores clásicos de la Literatura y la Filosofía. El Arte de amar de Ovidio es un ejemplo paradigmático de esta concepción. No obstante, el peso de lo artístico-creativo, no sujeto a normas ni a cánones, sigue siendo fuerte en la actualidad. Incluso los más estrictos analistas científicos reconocen el carácter inenarrable, individual y sublime del amor, en el que hay un componente poético y estético difícilmente traducible a los conceptos o leyes científicas. Es este componente el que sigue acercando aun hoy el amor a la creación artística.

Los productos o los efectos del amor, por otra parte, se han traducido muy frecuentemente en arte. Los varones, sobre todo los ilustres y poderosos, han levantado monumentos al amor de sus esposas o amantes, y en nombre del amor se han producido los más sublimes actos personales, incluyendo sacrificios. Pero, sobre todo, ha producido bellísimos discursos, poemas o textos que entraron en la historia de la literatura, es decir, en la historia de las artes.

También en su nombre se han iniciado guerras y se han cometido agresiones, homicidios y crímenes pasionales. El arte en su sentido positivo y las malas artes, como la otra cara del amor, han estado siempre estrechamente unidos, contrariamente a lo que desde un discurso fácilmente ideologizado se contrapone. El lema «haz el amor, no la guerra» se traduce frecuentemente en «haz el amor con unos y la guerra con otros» o "haz el amor y la guerra con la misma persona hasta conseguir dominarla». Las técnicas de seducción se han confundido con estrategias amorosas, pero, vistas desde la perspectiva científica o incluso desde un prisma moral, no dejan de ser estrategias de caza o de guerra más que de amor, ya que su objetivo final es la dominación y la posesión del objeto amado y no su consideración o respeto.

En cualquier caso, el sentimiento del amor ha traído consigo enormes costes y es inmenso el esfuerzo que hombres y mujeres han hecho en ocasiones para conseguir una relación con el objeto amado. La aceptación del dolor y hasta el deseo de muerte ha acompañado no pocas veces al sentimiento amoroso, mostrando una vez más sus contradicciones y su ambivalencia. Ambivalencia recogida en el discurso cotidiano y en la poesía y que se puede expresar con la bella y conocida metáfora de Antonio Machado: "Aguda espina dorada, quién te pudiera sentir en el corazón clavada». La vinculación del amor con la muerte se evidencia con otra metáfora no tan conocida, en este caso de Ovidio: "Yo pido para mí que el cruel amor mis estériles sueños interrumpa..." "Que cuando nadie estorbe me aniquile mi amada» (Ovidio, p. 249).

La ambivalencia y contradicción del ejercicio del amor se vuelve a manifestar en la ambivalente consideración social de los seductores y seductoras. Los especialistas en el arte de amar pueden llegar a ser peligrosos "donjuanes», mentirosos e inmorales, que merecen la condena social o la condena eterna. 
Pero alguien que no sepa amar en absoluto, de forma que no pueda producir algún sentimiento en la persona amada, tampoco posee ningún valor social. Cuando Erik Fromm afirma que si alguien ama sin producir a su vez amor, su amor no es amor, sino una desgracia, está aludiendo a la valía y eficacia de las técnicas amorosas.

Hay discursos sobre la esencia del amor en gran variedad de fuentes: filosóficas, literarias, sociológicas y psicológicas. Se podría decir que «existen prácticamente tantas definiciones de amor como personas han escrito sobre el tema» (Sangrador, p. 182). En los autores clásicos que vamos a analizar se encuentran saberes y referentes filosóficos, literarios y de psicología de la vida cotidiana, saberes enraizados en las distintas culturas que necesariamente han tenido que dar una respuesta a una cuestión tan central en las relaciones interpersonales como es el amor. Además de las culturas que definen el amor, las religiones y los códigos éticos religiosos reglamentan y codifican las relaciones amorosas.

Si sintetizamos la variada trayectoria histórica de este concepto, podemos señalar unas constantes en su definición que, a pesar de la multiplicidad de contenidos y versiones que se han formulado, traspasarían todas las épocas. A mi juicio, son las siguientes:

a) Se trata de un sentimiento refinado, complejo y con alto contenido estético y ético. Se le podría calificar de sentimiento «sublime». Pertenece al orden de lo psíquico intrapersonal, es decir, se vivencia como una emoción íntima. Es mucho más que un afecto positivo a otra persona, es un sentimiento muy complejo, muy elaborado, en el que se mezclan ideas, razones, consideraciones del objeto amado, percepciones de rechazo o aceptación, de valoración o desprecio, así como una larga serie de emociones difíciles de describir y con alto grado de producciones no controladas por el individuo, de origen inconsciente. No se trata de un afecto primario, sino de un sentimiento secundario, muy connotado por lo tanto, de dimensiones sociales. Podemos calificarlo de sublime porque no se traduce a un simple afecto ni se expresa con simples indicios fisiológicos. Es más bien inefable e inexpresable.

b) Implica una construcción peculiar y única de la persona amada. Esa construcción suele incluir una sobrevaloración y una dotación de prestigio superior a la conseguida objetivamente por la persona, es decir, superior a la que le confieren el resto de las personas del entorno social. Las cualidades del amado o amada son consideradas como algo muy valioso, que confiere a su vez valor a quien las ama. Amante y amado participan de una sobrevaloración personal que los acerca a la consecución de una suerte de completud imaginaria concebida como felicidad.

c) Necesita y produce un saber, unas técnicas refinadas de relación interpersonal. El inicio y el desarrollo de las relaciones amorosas precisa técnicas de seducción, atenciones o prácticas para maximizar el goce y técnicas para mantener las relaciones establecidas. El hecho de que dichas técnicas parezcan ser espontáneas y no aprendidas no reduce la eficacia de sus efectos. 
d) El amor es una creación. Los amantes no aman el objeto real, sino el que ellos mismos crean y la forma de amar que ellos mismos construyen. Lo que el amante quiere dar, lo que el amado posee son más bien cualidades creadas, imaginadas, que objetos reales. Las dimensiones imaginarias del amor son precisamente las más próximas a la creación artística. Se crean definiciones bellas, artísticas, de las relaciones amorosas, desplegando una serie de metáforas sobre su significado, y, lo que es aún más importante, se crean definiciones del propio objeto amado, reconstruyendo de una forma nueva y, mientras dura el amor, bella la idea de la persona amada. Las metáforas con las que los amantes se describen las mutuas cualidades o los sentimientos que vivencian en los actos de amor son precisamente creaciones artísticas. Por ello, las relaciones amorosas suelen producir expresiones poéticas y otros tipos de manifestaciones artísticas de una fuerza y una belleza inesperada o sorpresiva incluso para sus mismos autores. El mismo amor ha sido arte, ya que no sólo al expresarlo, sino también al «actuarlo», los amantes han creado arte.

La conexión del amor con el arte se establece, por lo tanto, desde una doble vertiente: por una parte, la propia concepción del amor, la creación del sentimiento amoroso y su expresión; por otra, las técnicas de la relación amorosa, las estrategias para la consecución del amor. Estas últimas son también artes, o más bien técnicas, y aunque apuntan a la eficacia de la acción destinada a conseguir el amor, pertenecen más bien a la "guerra», en su sentido metafórico, que al amor. Es decir, serían más propiamente «malas artes», artes de fingimiento, engaño, seducción y dominación. De nuevo se manifiesta la ambivalencia moral y las contradicciones del sentimiento amoroso con sus prácticas.

\section{CUATRO AUTORES CLÁSICOS Y UNA VOZ CONTEMPORÁNEA}

¿Es posible hablar de una Sociología del arte de amar? La Sociología del Arte considera las expresiones artísticas como un testimonio de las formas de pensar, de los deseos y expectativas y de las estructuras sociales de cada época. El arte se enraiza en el imaginario colectivo, en el espíritu de cada época, que no es otra cosa que la producción imaginaria. Los juicios de gusto y las elecciones estéticas son la base de clasificaciones, de maneras de hacer, de cánones estéticos y de maneras de verter las creaciones artísticas.

Por ello es posible hablar de unas formas de ejercer o de plasmar el amor que tendrían puntos comunes con el resto de las artes. Las grandes corrientes o movimientos culturales contienen no sólo unos ideales para la producción estética, sino un correlato de sentimientos que se mantienen también en el conjunto de las conductas amatorias y en la concepción de las relaciones amorosas.

En la cultura árabe nace, hacia los siglos IX y X, una forma de sentir y manifestar el amor que se ha llamado el amor bagdadí (de Bagdad) y que muestra un refinamiento más parecido al arte que a ninguna expresión «natu- 
ral» de emociones. En el sentimiento amoroso se incluye el ascetismo erótico, hasta llegar a renunciar al goce con la amada en aras de un sentimiento más sublime, que podía concluir en morir de amor. En los siglos XI y XII se inicia en Francia una manera de expresar el amor de los varones a las mujeres, que se ha denominado «amor cortés». Ese tipo de práctica, acompañado de un sentimiento peculiar, concuerda o se deriva de los ideales trovadorescos y constituye el inicio de un sentimiento de nostalgia por la separación, de sobrevaloración del objeto amoroso y de culto a su memoria y su presencia. En el siglo XIX, durante el Romanticismo, el sentimiento amoroso vuelve a cambiar de concepto $y$, de hecho, el amor, tal como se entiende en nuestros días y tal como es objeto de consideración por la psicología, se suele denominar «amor romántico» (Sangrador, 1993).

Por consiguiente, las «artes del amor» vistas desde la Sociología nos devuelven, como el resto de las artes, una visión de las épocas históricas en las que se crearon. Desde ellas nos podemos adentrar en las formas de organización de la sociedad, en los presupuestos que rigen las relaciones entre las personas, en la distribución de los poderes y de la organización social. A través del análisis de las «artes del amor» podemos conocer toda una tipología de las estructuras sociales y toda una manera de concebir las relaciones interpersonales, especialmente las relaciones mediadas por el género. Concepciones estéticas de la feminidad y la masculinidad, ideales de comportamiento de unos y otras, formas de relación entre los miembros del mismo o diferente estamento social, así como técnicas, oficio, saber y conocimiento aplicados al ejercicio de la sexualidad, aparecen con claridad en las obras que tratan sobre el amor.

$\mathrm{Si}$ analizamos algunas obras clásicas de la literatura que traten de este tema y recorran varias épocas históricas, podemos perfilar algunas líneas básicas en el planteamiento de la Sociología del Amor. El Kama Sutra es un tratado clásico sobre el amor y el erotismo. Producido dentro de la cultura hindú, recoge los presupuestos religiosos, éticos y filosóficos del hinduismo. Los textos de Ovidio Arte de amar y Amores nos acercan a las artes, técnicas y pautas de comportamiento amoroso en la Roma clásica. Ibn Hazm de Córdoba, en su obra El collar de la paloma, nos ofrece un tratado sobre el amor y los amantes, considerado una joya representativa de la cultura medieval musulmana en sus épocas de esplendor. Finalmente, dentro también de la cultura cristiana, Juan Ruiz, Arcipreste de Hita, en su Libro de buen amor, muestra los ideales estéticos y las pautas de comportamiento propios de las sociedades europeas del Medioevo.

En las cuatro obras clásicas citadas aparecen unos elementos comunes, que son los siguientes:

1) La concepción del amor. Los discursos sobre la esencia del amor y sus respectivas definiciones.

2) Los destinatarios del amor. Los roles de amante y amado y los límites $\mathrm{y}$ condiciones sociales de las relaciones amorosas. 
3) Las estrategias amorosas, las pautas sociales de las relaciones amorosas, es decir, las "técnicas del arte de amar».

\subsection{EL KAMA SUTRA: DIMENSIÓN ESTÉTICA Y EROTISMO}

\subsubsection{El concepto de amor}

De los cuatro clásicos que hemos citado, el Kama Sutra es el que más escasamente se refiere a la esencia del amor. Su pretensión es ofrecer un tratado científico y detallado sobre el erotismo y sus técnicas. No obstante, en sus cortas alusiones al concepto de amor subraya unas constantes bastante comunes con el resto de los autores: A) el carácter irracional, irresistible, incontrolable e inexplicable, pero no obstante positivo, placentero y benefactor, del sentimiento amoroso; B) la tendencia hacia la unidad entre las almas de los amantes; C) la conexión del amor con la libertad de elección de las personas por la que uno se siente atraído. D) la felicidad que confiere el amor se deriva de la realización del deseo amoroso y de la cercanía de quienes se atraen.

Por ello, el principal efecto social del amor es el cultivo de un tipo de relaciones interpersonales, que incluye una intención y una búsqueda de métodos para mejorar esas relaciones. Se traduce en un continuo ejercicio de superación, un preocuparse de la otra persona y un ininterrumpido esfuerzo de ingenio para mantener la llama del deseo siempre despierta. El placer se considera positivo, y en particular el placer del amor. En multitud de referencias se da por supuesto la bondad y los beneficios del amor, de las relaciones sexuales placenteras en todos sus tipos.

Teóricamente, el amor se admite para todos, hombres y mujeres, y se prioriza la dimensión amorosa frente a otras características de tipo social; por ejemplo, las conveniencias, pautas, normas o imposiciones de la sociedad. Así lo revelan las siguientes citas del Kama Sutra, que se refieren tanto al amor masculino como al femenino: "Sólo se puede ser feliz con una muchacha por la que uno se siente atraido, de lo cual se deduce, en consecuencia, que únicamente hay que casarse con la muchacha que se ama» (Kama Sutra, p. 97). "Una muchacha con numerosos pretendientes, se ha de casar con el hombre que ama y al que ella considera que debe rendirle obediencia por serle placentera» (Kama Sutra, p. 110).

El problema reside, no obstante, en la realización de dicho amor y sus condiciones. Los ideales culturales, así como los prejuicios sociales, priorizan los destinos del amor, eligiendo como destinatarios de él a personas que se adecuen a los ideales culturales, los estereotipos de belleza, las condiciones sociales valoradas en cada momento histórico. Todo ello condiciona los deseos de las personas, de los amantes, que interiorizan como suyos los criterios externos. Así, es generalmente deseable la belleza de acuerdo a los cánones sociales, la posesión de riqueza material o la posesión de educación y cultura. Las diferencias de clase están asimismo presentes dirigiendo los destinos del amor. Todos 
los clásicos, y el Kama Sutra incluido, aconsejan a los hombres buscar mujeres de su misma o superior clase o condición social.

El Kama Sutra denomina nayika a la mujer que se puede poseer sin pecar. Las nayikas pueden ser elegidas para fines de placer, pero también es lícito elegirlas como intermediarias para otros fines, algunos de ellos bastante inmorales vistos desde la ética actual. Pueden ser objeto de uso para fines económicos, políticos, venganzas personales, etc. Las nayikas más propias son muchachas, pero también pueden serlo las casadas por segunda vez y las mujeres públicas. Otras mujeres reciben la misma consideración que las mujeres públicas a estos efectos. Se trata de la «mujer caprichosa a la que muchos hombres han gozado antes que yo. En consecuencia, puedo dirigirme a ella igual que si se tratase de una mujer pública, pese a pertenecer a una casta más elevada que la mía (Kama Sutra, p. 46). En ese caso no se violan los mandamientos del Dharma (leyes sociales). Lo más peculiar e indigno visto desde la ética actual es la permisividad del uso de las mujeres y, en particular, de las relaciones sexuales con ellas para lo que se denomina un «motivo especial». Entre estos motivos especiales se encuentra el conseguir riquezas, ahuyentar o vencer enemigos, evitar la deshonra pública, evitar ser acusado de algún delito o, incluso, matar al marido para apropiarse de sus riquezas. "Por estas razones y otras similares, es lícito recurrir a las mujeres de otros hombres, pero en el bien entendido de que se permite por unas razones especiales y no por la pura satisfacción del deseo carnal»" (Kama Sutra, p. 47).

Las prohibiciones del goce con mujeres en el Kama Sutra revelan los diversos prejuicios de su época sobre las características físicas y sociales de las mujeres. Aparte del parentesco y de los defectos físicos o enfermedades, como la lepra o la enfermedad mental, son motivos de la exclusión de la relación de goce sexual el tener la piel demasiado blanca o demasiado negra o la frente prominente, las ventanas de la nariz grandes o la nariz chata. Otros motivos comportamentales, como haber cohabitado con otros, haberse mantenido oculta o simplemente manifestar públicamente el deseo de relaciones sexuales, son asimismo objeto de exclusión en las elecciones eróticas del varón.

\subsubsection{Las normas sociales}

Para entender las técnicas del erotismo en el Kama Sutra hay que tener en cuenta que la cultura hindú en los siglos en los que esta obra se escribió colocaba en una alta valoración la sensualidad, el placer, el disfrute de los sentidos, entendiendo esta dimensión estética y gozosa como una forma de integración del ser humano en el orden universal. Las normas de la existencia humana incluyen en la filosofía antigua hindú tres principios: el Dharma o dimensión religiosa, el Artha o dimensión de logro de bienes terrenales y sociales, y el kama o posesión del amor, el placer y la relación erótica. El kama se entiende como el disfrute de los objetos logrados por los sentidos, especialmente la con- 
ciencia del placer en las relaciones interpersonales y en las relaciones sexuales. El kama se recomienda en un conjunto de otras artes no amatorias, más bien estéticas, pero que contribuyen y forman parte de la sensualidad y se utilizan para incrementar y favorecer el kama. Se trata de las artes de la diversión y la distracción, junto con las que se ponen en juego en el ocio compartido y en las relaciones interpersonales en general. Para las mujeres, las artes del adorno, la decoración, los juegos, la magia, el sortilegio, el bien hablar, recitar, cantar y bailar, tocar instrumentos, son artes que se incluyen dentro del kama. Para los varones, también se incluyen dentro del kama los llamados oficios masculinos; entre otros, el arte de construir casas, minas y canteras, armas y otros instrumentos. También ellos favorecen de forma indirecta la práctica del kama propiamente dicho.

La estrategia amorosa básica y primaria, el cortejo, método de aproximación a la persona amada esencialmente masculino, está plagado de estrategias en las que se incluye el engaño, el cálculo detallado de los efectos del comportamiento, incluyendo el asustar y producir temor, la invasión de la voluntad y la persuasión de la amada mediante excusas falsas, la utilización de personas que puedan facilitar el acceso a la amada, la simulación de problemas o enfermedad del amante, etc. Una vez que el cortejo ha llegado a su fin y se ha conseguido el goce o el matrimonio, el Kama Sutra aconseja añadir a estas refinadas técnicas otras mucho menos sofisticadas que incluyen básicamente la custodia y vigilancia de la esposa.

La estrategia del cortejo no excluye a las mujeres, pero sus técnicas son bastante diferentes y, sobre todo, están llenas de dobles mensajes. Por una parte, ellas deben emplear todos los medios de que dispongan para hacerse amar y aprovechar todas las ocasiones para verse y encontrarse con el amado, regalarle flores, perfumes y otras pequeñas cosas. Por otra parte, queda bien claro que esto es lícito sólo para mujeres especiales; por ejemplo, las bien educadas y dotadas de excelentes cualidades pero que hayan nacido en una familia de clase inferior y sin fortuna y, por tanto, no sean solicitadas por varones de su mismo rango. También son lícitas estas técnicas si las utilizan las cortesanas, las prostitutas, en cuyo caso se aconseja también la iniciativa y diversas estrategias para conseguir dinero, librarse de antiguos amantes, etc. Es sorprendente constatar la similaridad de las prácticas aconsejadas a las cortesanas con las del cortejo masculino. Para la generalidad de las mujeres, se prohíbe la iniciativa y la anticipación al varón en la demostración de los sentimientos amorosos. Jamás debe ser la mujer la que se adelante a confesar sus sentimientos ni la que se ofrezca a él, ya que este comportamiento es despreciable. Es más, en condiciones normales, la mujer debe oponerse, ofrecer resistencia a todos los intentos que el varón haga para gozarla. Y, una vez que haya consentido en ser gozada, debe apremiar al matrimonio. 


\subsection{El ARTE DE AMAR DE OVIDIO:}

UNA PROPUESTA SOCIAL PARA LOS HOMBRES POBRES

\subsubsection{El concepto de amor}

Ovidio describe al amor como una fuerza avasalladora, personificada en los dioses Amor y Cupido, que pugna por someter la razón y la moralidad de los amantes (Amores, versículo 1.2). Esa fuerza somete a la cordura y al pudor. Con ello, el amor se connota de irracional, próximo al error, delirio y dolor. También se califica indirectamente de primitivo, puesto que restablece el comportamiento anterior a la socialización del pudor. Y, en cierto modo, de inmoral, ya que va acompañado por las artes de la seducción, engaño y también por el impudor. No obstante, dadas sus características, su fuerza y su inevitabilidad, lo más «razonable» es aceptar sus sentimientos y someterse a sus demandas, ya que cuanto más se resisten a él las personas, más cruel resulta el amor con ellas.

El sentimiento amoroso se entiende como unión con la persona amada. Unión en la realidad, fusión sexual, pero también unión metafórica: unión del nombre, unión de los actos, compartir lo mismo. La metáfora de la unidad se traduce también en ciertos actos materiales interpretados y connotados socialmente como signos de amor. "Yo cogeré el primero las copas que tú entregues y por donde hayas bebido tú, beberé yo» (Amores, 1.4).

El amor se produce en la libertad y es contrario a los lazos de obligación impuestos por las relaciones sociales, en particular por los matrimonios basados en las reglas de la conveniencia y en los condicionamientos de las castas y los estamentos sociales. De este modo limita en parte con lo furtivo, lo escondido, lo clandestino. La expresión más genuina del amor está en su oda «Cena con el marido de la amada" (pp. 148-153), en la cual se contrastan continuamente los actos de amor furtivos entre los verdaderos amantes con los actos forzados por la relación social establecida. «Lo que me das a mí furtivamente se lo darás a él forzada por la ley» (p. 152). Del mismo modo, tampoco el amor debe ser pagado de ninguna manera. La libertad significa ausencia de obligaciones, regalos o contratos económicos entre los amantes. El pago significa mezquindad y es extraño a la inocencia, espontaneidad y claridad expresadas en la metáfora, sin duda erótica, de un niño desnudo que no tiene bolsillos en que guardar el dinero (Ovidio, p. 185).

El amor es generoso, es decir, no plantea muchas restricciones en cuanto a las posibles elecciones amorosas. Existen muchos motivos para el amor, casi la generalidad de las mujeres pueden ser amadas. No obstante, como es de esperar en una sociedad tan marcada por las diferencias sociales, en la que existen siervos, la excepción son las esclavas, las siervas o las de baja condición social. "¿Qué hombre libre querrá entrar en tratos de amor con una sierva y abrazar su espalda marcada por el látigo? (Ovidio, p. 238).

El amor, finalmente, es ambivalente, contradictorio. El deseo es recurrente, 
pero también doloroso. Las consecuencias del amor no son menos ambivalentes. Sus dos principales efectos son la fuerza personal y la esclavitud. El amor fortalece a las personas, pero el coste de la relación es la atención estrecha a la otra persona y a sus necesidades. Hay que ser «soldado del amor», y ejercer un servitium de amor. Disciplina, sumisión, trabajo, pero muy especialmente atención a las necesidades eróticas de la amada.

\subsubsection{Las reglas sociales}

Para Ovidio, como para el resto de los autores tratados, la primera regla social que rige para el amor es la «elección de los iguales» y el rechazo de los «inferiores». En concreto, la norma es elegir mujeres de la misma clase o condición social. La desigualdad en el amor se legitima, no obstante, si se produce entre un varón y una mujer de superior condición, ya sea de poder o de belleza. Los ejemplos que nos presenta, procedentes de la mitología clásica, son bien reveladores. Uno de ellos es el de los amores de la diosa (inmortal) Nereida con el rey (mortal) Ptio. Otro, el de la bellísima Venus con el deforme Vulcano. Este tipo de relaciones son bienvenidas y muy deseadas, lo cual contrasta fuertemente con el repudio de los amores con esclavas: "que los dioses me den algo mejor, si tuviese deseo de ser infiel, que disfrutar con una amiga ruin, de clase despreciable» (p. 238). O los versos anteriormente citados: "¿qué hombre libre querría entrar en tratos de amor con una sierva y abrazar una espalda marcada por el látigo?» (p. 238).

Es interesante resaltar que, así como algunas mujeres resultan excluidas del amor, todos los varones están destinados a amar. Precisamente, Ovidio dedica su arte de amar especialmente a los hombres pobres, para que éstos tengan disponibilidad de amar. Quizá el más chocante contraste entre lo sublime y lo bajo, entre el sentimiento de completud y el goce ético y estético del amor y la simple práctica sexual sexista de posesión de los objetos amorosos se encuentra en Ovidio, quien con bastante ironía, o quizá escepticismo y tristeza, declara que su tratado sobre el amor sólo es para los amantes pobres. Y es que el dinero consigue todo aquello que parecía tan sublime. «No he venido yo a ser preceptor de amor para los ricos. El que va a hacer regalos / para nada precisa mi tratado. I tiene la inspiración consigo mismo..." "Soy poeta de los pobres porque pobre yo amé» (Ovidio, p. 444).

Las reglas más importantes y más detalladamente descritas están destinadas a los varones y, si tenemos en cuenta su sofisticación y finura, no extraña que hayan podido ser muy útiles incluso para los «hombres pobres». Tanto la aproximación a la amada como el inicio de la relación amorosa y su mantenimiento están sujetos a cuidadosas reglas que exigen una planificación detallada y ciertas dosis de ayuda y complicidad. Además de las casamenteras, es frecuente aludir a la complicidad libre o pagada de las esclavas, y no pocas veces al acoso y al chantaje. 
La primera regla específica consiste en desconfiar de las mujeres. Varios ejemplos de la realidad y también de la mitología clásica sirven para ilustrar y fundamentar este principio básico. Las mujeres fingen, como se demuestra en los amores adúlteros; las mujeres cuyo ardor pasional ha destrozado las vidas de los hombres, los incestos e incluso las pasiones inmorales o aberrantes (ej., la pasión de Pasifae por un toro). La sospecha es la premisa de la relación, que justifica posteriormente la vigilancia y el control de las mujeres. La cantidad de ejemplos de este tipo, así como su variedad, no excluye las más modernas versiones de comportamientos persecutorios de mujeres explicadas por la simple conclusión de que «la pasión femenina es más intensa y tiene mayor furia que la nuestra" (Ovidio, p. 398).

La segunda regla es hacerse amigo de la esclava. Las esclavas harán la conquista más fácil. Es la táctica de la aproximación indirecta, mediatizada y facilitada por una información íntima sobre la mujer que no tiene su correspondencia a la inversa. Se trata de una justificación de la desigualdad de recursos entre el amante y la amada. Esta táctica, ya de por sí de dudosa legitimidad, se complica aún más, deteriorándose su calidad moral cuando el amante finge amar y seduce a la esclava de la mujer verdaderamente elegida y la coloca en una posición difícil y proclive al castigo y la desvalorización social. El poema sobre Cipasis, la esclava de la amada Corina, revela claramente el papel que las esclavas podían desempeñar en las estrategias masculinas de la conquista amorosa. Tras seducir a Cipasis, como estrategia para conseguir el amor de su dueña, Corina, el amante niega públicamente su relación con la esclava. Esta negación pública evita el castigo de la esclava, pero a cambio el amante le pide que le siga otorgando sus favores, bajo amenaza de delatarla. La esclava queda así atrapada por un doble lazo, la amenaza de ser delatada y la obligación, no obstante, de seguir manteniendo una relación sexual peligrosa y sometida al chantaje (Ovidio, pp. 237-242).

Las palabras que Ovidio utiliza para justificar su utilización de las esclavas estremecen por su impiedad: "a ella (la esclava) corrómpela tú con promesas, a ella rogando tú corrómpela. Si ella quiere obtendrás lo que pretendes fácilmente» (Ovidio, p. 399). La razón es bien simple, consiste en que al hacer a la esclava partícipe del acto ilícito, ella misma queda atrapada sin posibilidad de ser delatora. "El pájaro no es capaz de huir cuando tiene las alas engomadas. Quédese el pez, ya malherido, sujetado por el anzuelo que él mismo ha mordido" (Ovidio, p. 401).

Las siguientes reglas son de carácter más concreto y aluden a los momentos en que es mejor abordar a la amada, y las formas, entre las cuales se aconseja evitar los regalos al principio y fomentar la comunicación, la elocuencia, las cartas o los encuentros. En esta fase tiene lugar todo el despliegue de halagos, fingimiento, promesas, adulación, sobrevaloración ficticia de la amada, etc. La inmoralidad de estas prácticas se pone de manifiesto en la defensa explícita del engaño: "no te importe fingir con palabras. Busca, con cualquier medio, que te crea» (Ovidio, p. 418). Conviene subrayar que se legitima en las relaciones con 
las mujeres lo que se considera ilícito en el contexto de las relaciones interpersonales: «sin recibir castigo, sólo con las mujeres debéis jugar. Tan sólo en ese caso la lealtad ha de dar más vergüenza que el engaño» (Ovidio, pp. 420-421).

Finalmente se describen una serie de normas que tienen que ver con el forzamiento y la violentación de la voluntad de la amada. Desde el prejuicioso presupuesto básico de que a las mujeres les gusta que las fuercen, Ovidio aconseja siempre ir más allá de lo que la amante le da al amado, tratando incluso de no merecedor de amor al amante (varón) que no lo hace: «El que toma los besos, si no toma lo restante también merecería perder incluso aquello que le han dado" (Ovidio, p. 422). Para justificar estas actitudes, de nuevo acude a héroes y personajes de la mitología que ilustran y refuerzan ese supuesto deseo de la mujer de ser forzada. El éxito amoroso de personajes que han raptado a sus amadas, como Aquiles, Príamo y Pelión, son ilustres ejemplos de lo que estamos diciendo.

Las estrategias aconsejadas por Ovidio se pueden resumir en las siguientes: A) manejo de la fachada, el semblante, mediante el fingimiento; B) cultivo de las artes de la relación interpersonal, y C) vigilancia y control de la amada, hasta llegar al forzamiento de su voluntad. La tercera de estas estrategias ya va dirigida únicamente a los varones desde su mismo enunciado. Pero las otras mantienen también importantes diferencias si quien las utiliza es un hombre o una mujer.

El manejo de la fachada, el carácter superficial, incluye tanto el aspecto físico como las formas de presentarse. La limpieza, el aseo, el bien hablar, la elocuencia, la adulación, el mostrarse generoso, la promesa aunque sea falsa, la invención de fantasías o incluso sueños en los que aparece la amada, la demostración de aprecio aunque sea fingida o excesiva. Todo ello vale en este terreno, tanto para hombres como para mujeres. Las actitudes básicas desde las que ambos deben partir son, no obstante, bastante diferentes. Los hombres deben desconfiar de las mujeres, y éstas, provocar celos, inseguridad y temor a los varones.

A los varones les basta con ser limpios y mostrar en todo momento su iniciativa. Las mujeres deben mostrar una complicada serie de atributos para ser atractivas. Deben cuidar en primer lugar la belleza física, cultivar el cuerpo en todas sus manifestaciones, el peinado, los tintes, las pelucas, los vestidos, sus colores y sus formas, los cosméticos, el disimulo de los defectos físicos. El disimulo de los defectos físicos debe hacerse también en los varios actos de la relación amorosa, incluso en todas las formas de relación interpersonal: no reírse abiertamente si se tienen defectos en la boca, no subrayar con ademanes claros sus palabras las que tienen dedos gruesos... Es decir, toda una serie de normas de contención para no mostrar las imperfecciones. Incluso la expresión de las emociones como la alegría, la tristeza o el enfado debe estar reglamentada. Hay que reír y llorar con gracia y no se permite el enfado. La furia afea, la arrogancia asusta y la tristeza aborrece. Conviene contener en el semblante los ánimos rabiosos: "sienta bien una cándida paz a las personas y a las fieras una ira treme- 
bunda. Con la ira se inflaman las facciones, las venas se ennegrecen con la sangre, echan chispas los ojos con más saña que el fuego de Gorgona» (Ovidio, p. 532). La mujer digna de ser amada es la mujer sumisa y contenida. La mujer que llora con gracia y dulzura y que no se enfada. La sumisión se disfraza de belleza y atractivo, y se aconseja tanto en los momentos de cortejo previos a la relación sexual como en la misma relación sexual. Sobre el cortejo, las recomendaciones a las mujeres en la siguiente cita son suficientemente expresivas: "míralo si él te mira, sonrie amablemente si él sonrie. Te hace una señal con la cabeza, devuélvele el mensaje recibido" (Ovidio, p. 533). En el acto sexual, la actitud de sumisión se confunde y se mezcla con la belleza y el atractivo cuando se aconseja adoptar aquellas que ocultan las imperfecciones de la belleza de la mujer y las que favorecen que esté más atractiva a la vista del varón. "Las de hermosas facciones tiéndanse boca arriba. Se mostrarán de espalda las que por eso gustan. Llevaba Milanión sobre los hombros las piernas de Atalanta; si son bellas, han de ser contempladas de ese modo" (Ovidio, p. 552). Y así ocurre con una larga serie de aspectos y calidades de la mujer: los pechos, los costados, el cuello, todos ellos se deben colocar de la forma más favorable para el disfrute del otro. Contenerse, mentir y fingir son las actitudes que debe manifestar durante el acto sexual. En el momento de la demostración o expresión del placer: "Tiernas exclamaciones y gozosos murmullos no cesen y tampoco se silencien las palabras procaces en medio de los goces" (Ovidio, p. 553). "Finge dulces placeres con suspiro engañoso... hazlo creible con tu movimiento, incluso con los ojos" (Ovidio, p. 554).

Las mujeres deben hacer otra función únicamente destinada a ellas. Deben ser «entretenedoras». Deben cultivar las artes de entretenimiento, de hacer la vida agradable a los interlocutores. Entre estas artes y aprendizajes se encuentran el pronunciar bien, cantar, bailar, tocar algún instrumento (de menor importancia), recitar poesía y escribir cartas de amor. Asimismo, aprender juegos, «manejar los dados sabiamente» y con «ánimo sereno». Es decir, sin irritarse ni mostrar ambición ni ansia de ganar y sin mostrar tampoco dolor por haber perdido. "Yo he visto muchas veces que se mojan las mejillas de lágrimas (por haber perdido). Que Júpiter aleje tan feas faltas de vosotras, que os preocupáis por agradar a un hombre» (Ovidio, p. 521). No sólo la sumisión, sino la suavidad y la contención son los rasgos más característicos de esta función de entretenedoras.

Finalmente, las mujeres deben ser especialistas en el arte de la inseguridad. Deben saber seducir, provocando celos, jugando a manifestar y ocultar los sentimientos. En el comienzo de las relaciones, la seducción consiste en un complicado juego de mostrase y ocultarse, de aceptar y negarse, de llegar tarde para ser esperada, etc. Mas tarde, cuando la relación está ya establecida, comienza la estrategia de introducir dudas sobre los sentimientos hacia el amante, inseguridad acerca de la duración de la relación, acerca de la posible existencia de otro amante más valioso y apreciado, de la negación de la relación sexual sin aparente motivo. En definitiva, el arte de crear una definición de la situación en la que nada quede suficientemente claro ni sea definitivo. 


\subsection{EL LIBRO DE BUEN AMOR DEL ARCIPRESTE DE HITA: METÁFORAS DEL JUEGO Y LA CAZA}

\subsubsection{El concepto del amor}

Juan Ruiz, en su Libro de buen amor, incluye al amor entre las emociones y los sentimientos placenteros, beneficiosos y sanos. Es asociado con la alegría y el placer. La alegría y el bienestar se asocian a la compañía y el placer, a la sexualidad. Las bondades de la compañía son descritas con abundante entusiasmo, atribuyéndolas a los seres humanos y también generalizándolas a los animales, las plantas e incluso las cosas. Los siguientes versos expresan más que cualquier comentario:

«hay un refrán que afirma lo que yo os digo ahora:

un ave si está sola ni canta ni llora;

el mástil sin la vela no puede ir a toda hora;

la berza, con el agua de la noria, mejora».

$$
\text { (Juan Ruiz, p. 60.) }
$$

No obstante, este sentimiento se encuentra lejos de lo que se denomina "amor romántico», ya que la elección del objeto amoroso está mediatizada, como en el resto de los textos, por las condiciones sociales. La regla de la igualdad sigue presente en Juan Ruiz, que vuelve a reforzar las reglas de la estructura social. Aunque teóricamente al amor le gustan todas las mujeres, las mujeres villanas no deben ser elegidas, ya que se consideran torpes o ignorantes. Las mujeres de este tipo sólo deben tomarse si no hay otro remedio. "Si pudieres no quieras amar mujer villana, pues de amor nada sabe, palurda y chabacana» (Juan Ruiz, p. 105).

El catálogo de tipos femeninos del Arcipreste de Hita puede ser leído como una lista de preceptos sobre elecciones y exclusiones de determinadas mujeres, como un catálogo de criterios en los que se pueden basar las preferencias y las exclusiones amorosas de los varones. Además de las de baja condición social, las monjas, las feas, las que tienen ciertas características físicas desvalorizadas por los ideales culturales o los simples prejuicios se excluyen de ser elegidas como objetos amorosos. La noble discreta y despechada, la casquivana que se fue con el mensajero, la dama virtuosa y recogida son ejemplos de elecciones amorosas inadecuadas, precisamente por las características propias de la mujer. La sucesión de aventuras fracasadas con estas mujeres se puede tomar también como un aviso sobre las reglas sociales que sitúan a cada tipo de mujer dentro de unos condicionantes sociales. 


\subsubsection{Las reglas sociales}

Como en el caso de Ovidio, parece señalar el Arcipreste la riqueza y el poder social como los principales medios para conseguir el amor. Los regalos, los obsequios y las delicadezas son las principales técnicas y procedimientos para dirigirse a la amada. "Hace mucho el dinero, mucho se la ha de amar" (Juan Ruiz, p. 113); "si tuvieses dinero tendrás consolación, placeres y alegrías y del papa ración" (Juan Ruiz, p. 113).

Porque el arte de amar se convierte en el arte de conquistar y conservar objetos, piezas valiosas utilizando ciertas técnicas y haciendo uso de ciertas artes. Ciertas técnicas de relación interpersonal son utilizadas para conseguir las mejores opciones amatorias. Entre ellas, la cortesía, la delicadeza y el arte de rendir la voluntad de los amantes. El ejemplo más evidente de la conexión del amor con las estrategias y métodos para conseguirlo es la figura de los mediadores, personas expertas en conseguir la rendición de una persona a su amante, y lo hacen por dinero, tratando además de conseguir la «pieza», la conquista, al más bajo precio. Esta figura está representada por las alcahuetas, mujeres viejas y socialmente desvalorizadas, a las que se adorna de todo tipo de calificativos negativos, pero, no obstante, se consideran necesarias. Tanto ellas como sus artes son considerados de baja calidad moral, ya que utilizan el engaño, el fingimiento, la preparación cuidadosa de la situación para engañar mejor; y esto no solamente lo aplican con las jóvenes, a las que presentan a su propuesto amante rodeado de todas las virtudes y condiciones necesarias para ser amado, sino a los propios amantes, varones que son los que encargan sus servicios. En esas mujeres se encarna todo el estereotipo negativo de la psicología femenina. Muchas veces ellas son la metáfora de los caracteres femeninos, a los que se proyectan las artes de la simulación, la traición, las tretas, el chantaje y demás «malas artes» de seducción.

El galán ha de ser osado y persistente en su trato con la dama a quien corteja, vigilante y desconfiado como quien se enfrenta con una pieza de caza. En la osadía intervienen técnicas planificadas de jugador que coloca al contrario en apuros o que le hace perder algo o caer en la trampa. Entre ellas predominantemente, las técnicas típicas del acoso, algunas de ellas bordeando en la seducción perversa. "Haz a la dama un día la vergüenza perder / pues esto es importante si la quieres tener / una vez que no tiene vergüenza la mujer / hace más diabluras de las que ha de menester?» (Juan Ruiz, p. 110). La osadía abarca más que la insistencia y la iniciativa; abarca también la bravuconada, el halago, la lisonja, los cumplidos y la cruda mentira acerca de las cualidades o las posesiones del amado. "Con lo tuyo y lo ajeno preséntate adornado, pero que ella no sepa que lo llevas prestado. Si tu vecino ignora lo que tienes guardado, encubre tu pobreza con mentir colorado" (Juan Ruiz, p. 132). Es decir, toda una desvalorización de la verdad y elogio de la mentira bastante sorprendente por otra parte, ya que quien lo afirma es un clérigo. La iniciativa invasora u osadía del varón se justifica, entre otras cosas, porque se atribuye a la mujer una estrategia 
de inicial rechazo y resistencia a los amantes, un inicial fingimiento de desinterés, una maña de sentirse enojadas y molestas, una manifestación estratégica de desdén y esquivez. Todo ello conecta muy bien con el estereotipo de la mujer que desea verse forzada, obligada y, en cierto modo, violentada. "Mejor quiere la dama verse un poco forzada que decir, lo que quiere, como desvergonzada"; "todas las hembras tienen semejantes maneras, / al comienzo del caso nunca son placenteras / se fingen enojadas y son muy regateras" (Juan Ruiz, p. 131).

Coherentemente con la percepción de este contexto de engaño continuo, en un escenario que más bien parece el de la caza, a las mujeres se les aconseja la desconfianza del varón, la prevención de su voracidad. La alusión a la caza se hace patente en la metáfora del varón comparado con un león que engaña a un asno, al que, tras aprovecharse de su buena fe, de su confianza y de su ignorancia, termina matando y devorando.

Si descendemos del terreno de las metáforas a la realidad, una de las más graves consecuencias de amores inadecuados para las mujeres es la pérdida de la fama y del buen nombre. La difamación, el escarnio, son los principales daños producidos por haber confiado demasiado y haber entregado de forma necia sus favores a los varones voraces. La iniciativa, pues, no tiene sentido; más bien, adquiere especial relevancia guardarse de la iniciativa de los demás. No obstante, en algún breve pasaje se lamenta la falta de osadía de la mujer y su tendencia a huir de lo prohibido, ya que ese rasgo impide a la mujer ser amada.

Las relaciones amorosas están impregnadas de desconfianza y de dificultades, de experiencias fracasadas. La historia de la fracasada relación con la monja doña Garoza es un paradigma ejemplificador de la dificultad de las relaciones amorosas y de la desconfianza que en ellas debe reinar. Tras una larga serie de entrevistas con la alcahueta Trotaconventos, una serie de intentos, de conversaciones, de mediaciones entre el amante y la monja, lo único que se consigue es un "limpio amor», que incluye ruegos a Dios, abstinencias y acciones piadosas, pero no las locuras del mundo ni los amores mundanos que el amante pretendía. La desconfianza es la regla de oro del amor. Desconfianza del amante, sea hombre o mujer; desconfianza de los mediadores, los recaderos o las alcahuetas.

\subsection{EL COLLAR DE LA PALOMA DE IBN HAZM: EL PLATONISMO MUSULMÁN}

\subsubsection{El concepto del amor}

Ibn Hazm de Córdoba reivindica el amor por considerarlo importante y positivo, tanto en su misma esencia como por sus señales y sus consecuencias. El hombre más feliz es el que tiene una mujer a la que ama y que le ama, es el hombre implicado en una relación amorosa. La expresión del amor es asimis- 
mo algo importante, positivo y bello. Nada hay en el mundo que se pueda equiparar a la solicitud del amante con la persona amada. Se trata de algo universalmente reconocido y que produce fascinación, turbación y asombro.

La trascendencia social del amor se reconoce, además, valorando y subrayando la relevancia de las personas que han sido amantes; grandes califas, príncipes, imanes y personas importantes se cuentan entre los amantes. El amor de estos enamorados ha producido grandes aportaciones a la historia de los musulmanes, aunque en algunos casos ha sido la causa de graves conflictos y de desgracias. Los amores causan conflictos porque subvierten o violan las normas sociales. Los amantes, llevados por la pasión, no cumplen con sus deberes de padres, hijos, esposos o gobernantes, con lo que causan la ruina de las familias o la tragedia de los pueblos. No obstante, nada hay que cuestione seriamente que el amor es un sentimiento elevado y sublime.

El amor "consiste en la unión entre partes de almas que en este mundo andan divididas en relación a como primero eran en su elevada esencia» (p. 101). Es la concepción platónica, la misma que supone la identidad de las almas que estuvieron unidas en un mundo superior y que tienden en éste a la unión. La causa del amor es la belleza. La belleza corporal es uno de sus más fuertes impulsores, pero el amor no se queda en ella y asciende a algo más sublime, otro tipo de estética. En definitiva, algo que radica más allá de lo superficial físico, «en la misma esencia del alma».

El amor se manifiesta por unas señales claras en la relación con el amado: tendencia hacia el amado, búsqueda, seguimiento del amado en el comportamiento y también con la mirada. Se manifiesta asimismo en la transformación de la personalidad de los amantes hacia rasgos positivos: los tacaños se vuelven generosos, los cobardes se envalentonan, los sucios se vuelven limpios y los ásperos se vuelven sensibles. Es decir, la personalidad se torna más sociable y tolerante, aunque también puede ocurrir lo contrario, apareciendo disputas entre los amantes por motivos nimios. La explicación de este comportamiento, según Ibn Hazm, es de carácter lógico, ya que los opuestos están siempre muy próximos, el amor próximo al odio, y viceversa. Las vivencias de felicidad o de carencia dependen estrechamente del amado, de su presencia o su ausencia y de su comportamiento con respecto al amante. El amor se liga de este modo al sufrimiento, incluso a la muerte. Las cuitas de amor pueden llevar a la muerte, el amante puede desear la muerte como máxima felicidad tras perder al amado o por el hecho de que éste no le corresponda.

\subsubsection{Las reglas sociales}

En este autor clásico, así como en la obra contemporánea que hemos elegido como contraste, la de Arundathi Roy, se produce una «negación de las reglas sociales» del amor. La representación del amor es romántica. No importa la desigualdad social entre los amantes; es frecuente el amor con las esclavas; 
posible el flechazo entre seres desconocidos e inesperados; los amantes son apresados por pasiones no siempre correspondidas pero permanentes y dolorosas. Los amantes permanecen fieles al amado durante toda la vida; salvan infinitas barreras para conseguir el amor; consiguen ablandar los más duros corazones con la sola demostración de la pureza y la fuerza de sus sentimientos. Todo ello y otras demostraciones más de la sublimidad, pureza y alto contenido ético del sentimiento amoroso se expresan en este texto a través de bellas fábulas y metáforas. Esta obra muestra una faceta optimista del amor, ya que en multitud de ocasiones el sentimiento logra sobrepasar los múltiples obstáculos sociales y sobrevivir. Por ello, la consideración de las reglas sociales en este texto tiene mucho menos sentido que en el resto de los textos analizados. Bien es verdad que eso no significa que el amor en los momentos en que dicho libro fue escrito, siglo $\mathrm{X}$, y en el contexto de la España musulmana, fuese como presenta nuestro autor. Emilio García Gómez, ilustre arabista que prologa y versiona una de las ediciones de esta obra (op. cit.), alude a la inadecuación de la poesía para expresar las condiciones de la realidad social en dicha época, siendo lo más probable el distanciamiento entre los contenidos poéticos presentes en el texto, muy próximos al deseo de amor y a su concepto, y las reglas, excluidas en el texto pero muy presentes en las condiciones sociales de la cotidianeidad.

\subsection{EL DIOS DE LAS PEQUEÑAS COSAS DE ARUNDHATI ROY: LA NEGACIÓN TRÁGICA DE LAS REGLAS DEL AMOR}

Esta obra es, en primer lugar, un excelente retrato de la India contemporánea. Con expresivas pinceladas de fuerte carga emotiva, la autora va desplegando la problemática social, religiosa y política que afecta a una saga familiar prototípica de un gran centro urbano. Con respecto al tema que nos ocupa, una de las cuestiones más valiosas que contiene es una metáfora en la cual el amor muestra una radical incompatibilidad con las reglas sociales y una negación sistemática de sus leyes, negación que siempre tiene un final trágico. La imposibilidad de realizar el amor o, lo que es lo mismo, el abocamiento de todo amor verdadero a la marginación o la muerte queda cristalizado en las trayectorias de los distintos amantes. Las únicas personas que consiguen mantenerse en el seno de la estructura social, ejerciendo papeles no ya valiosos, sino simplemente válidos, son las que aceptan las normas sociales, las que siguen las leyes del amor. Leyes sumamente importantes para la autora, que alude a ellas casi con las mismas palabras en cuatro partes de su obra: «Leyes que determinan a quién debe quererse, y cómo. Y cuánto» (Arundhati Roy, pp. 47, 49, 208, 370). Pero quienes aceptan esas leyes están abocados al fracaso de su amor. Sus relaciones se rompen o no están regidas por el deseo mutuo de los amantes, quienes se mantienen en ellas por constricciones sociales, por miedo o por cumplir otras demandas ajenas al amor. Sólo los transgresores alcanzan el amor. Los hermanos gemelos que transforman su amor fraternal en 
amor erótico, la mujer de clase media que ama a un hombre de una casta inferior a la suya, son los que hacen real el amor, pero a un altísimo coste. Tan alto que incluye el desprestigio, la marginación social y la muerte.

El amor aparece como un episodio histórico que cuestiona las leyes, que subvierte las reglas, haciendo aparecer demonios y fuerzas misteriosas que se creían desterradas para siempre, y arrastra a los amantes fuera de lo normativo, lanzándoles a la negación de su identidad social o, en algunos casos, a la destrucción de sus vidas. De una forma sin duda poética, metafórica, pero con un lenguaje muy de nuestros días, Arundhati Roy parece afirmar lo que de otra forma afirmaron los clásicos. La radical diferencia entre el sentimiento del amor y las estrategias, normas y prácticas sociales. El hecho de que la normativa social alcanza de lleno al amor limita la libertad de elección, excluyendo la posibilidad de muchas relaciones deseadas, estableciendo leyes que califican de indeseables o impensables ciertas formas de amar. Son los mismos códigos que regulan las relaciones y que marcan otros límites entre personas diferenciadas por las estructuras sociales. De vez en cuando, lo inconcebible se hace concebible y ocurre lo imposible, pero, eso sí, de forma momentánea o temporal, ya que finalmente acaba restableciéndose la maquinaria normativa sin importar cuánto dolor o sufrimiento pueda causar. Es algo que los amantes saben, aunque su sentimiento sea más fuerte que su «razón»: «La biología dispuso la coreografía de la danza. El terror marcó el tiempo. Dictó el ritmo con que un cuerpo respondía al otro. Como si supieran que, por cada estremecimiento de placer, pagarían con una medida igual de dolor. Como si supieran que, cuanto más lejos llegasen, más atrapados estarían» (Arundhati Roy, p. 377).

La crueldad y la implacabilidad de los castigadores, que con frecuencia son personas de la misma familia de los amantes, se pueden entender también como una transgresión de los sentimientos de amor y piedad esperables entre personas del mismo grupo familiar, pero en realidad únicamente están mostrando la jerarquía de las leyes, están mostrando que por encima de los lazos afectivos se sitúan las demandas sociales.

\section{RECAPITULACIÓN: DEL SENTIMIENTO SUBLIME AL AMOR COMO DOMINACIÓN DEL OTRO EN EL MARCO DE LAS ESTRUCTURAS SOCIALES}

Siendo el amor algo tan sublime como aparece en la mayoría de los textos, sorprende la cantidad de condicionantes a los que está sometido cuando se hace real y la poca espontaneidad con la que se abordan los comportamientos amorosos. Por una parte, el sublime amor está marcado por condicionantes de clase social y de género que definen quién, cómo y a quién se puede amar. Por otra parte, las pautas amorosas distan mucho de mostrar la exquisitez del concepto y se convierten en estrategias de bajo nivel moral en las que abunda el fingimiento, el engaño y el forzamiento de las voluntades. 
No todas las personas parecen tener las mismas oportunidades para convertirse en amantes. Las reglas sociales limitan y excluyen a los potenciales amadores. Unas veces de forma explícita y otras de una manera más sutil. Los varones son los amadores por excelencia. Todos ellos están destinados a ser amantes, y las condiciones para serlo son mínimas. Por el contrario, varios tipos de mujeres aparecen excluidas o excluibles de las relaciones amorosas. Las villanas, las esclavas, las monjas, las consideradas feas o las que tienen ciertas características físicas desvalorizadas por simples prejuicios, se excluyen de ser elegidas como objetos amorosos. En consecuencia, las estrategias que los clásicos aconsejan para conseguir el amor tienen como principal referente a los varones, los supuestos lectores de los tratados son varones, el lenguaje con el que se dirige a los lectores es un lenguaje para varones, y sólo ellos parecen ser los principales destinatarios de todo el discurso amoroso. Dos textos, el Kama Sutra y el Arte de amar, incluyen a las mujeres explícitamente. En el primer caso, para aconsejar a éstas que aprendan el arte del kama y, en el segundo, para reprocharlas no haber aprendido el arte de amar. No obstante, la principal atención que se presta a las mujeres en los dos textos consiste en promover los aprendizajes que puedan hacer más agradable la relación a los varones. En raras ocasiones aparecen ellas como seres libres que eligen los destinos de su amor.

El amor parece un sentimiento básicamente masculino y especialmente ligado a la sexualidad. En todo momento el protagonista del sentimiento y quien muestra la iniciativa amorosa es el varón. El cortejo es masculino. El placer del amor es básicamente para los varones y reside en la relación con las mujeres. Los beneficios del amor, así como el potencial transformador que el amor posee, parecen aprovechar mucho más a los varones. Para ellos puede haber una transformación total en positivo de su personalidad: los cobardes se transforman en valientes, etc.; para las mujeres nada de esto se cita; por el contrario, los únicos beneficios del amor para las muchachas son sociales: la muchacha casada por amor rendirá obediencia a su marido porque le resulta placentero y su marido tendrá verdadera autoridad sobre ella.

La primera regla que define a quién se puede amar es la regla de elección de los iguales. Sólo las mujeres de igual o superior condición social son dignas de ser amadas. Todas ellas, no obstante, pueden ser utilizadas como mediadoras de formas lícitas o ilícitas para conseguir los objetos de amor apropiados, los que se acomoden a las reglas. La desigualdad sólo se tolera si favorece a los varones y se ve con simpatía y aprobación que los varones aspiren a conseguir mujeres de clase, educación o posición social superior.

Todos los autores abundan en la descripción de estrategias prácticas, recetas, a poner en juego en el inicio y el transcurso de las relaciones. Se trata básicamente de técnicas de seducción y chantaje. Tanto unas como otras suelen ser de un carácter moral muy dudoso, desbordando en muchos casos los límites de la ética. Estas técnicas manifiestan unas importantes diferencias según se destinen a los varones o a las mujeres. Fingimiento, engaño, expresión controlada y 
contenida de las emociones, contención de la expresividad y sumisión son las reglas en las que se resume el arte de amar para mujeres. Iniciativa a cualquier precio, incluso asumiendo el engaño y las promesas exageradas o que nunca se van a cumplir. Halago engañoso, desconfianza, deslealtad, forzamiento de las situaciones y las voluntades son las reglas en las que se resume el arte de amar para varones.

Si bien el sentimiento amoroso, tal como se describe en su concepto, despierta un enorme respeto, la imagen de hombres y mujeres actuando el amor resulta bastante inquietante y suscita un claro sentimiento de desconfianza y precaución. Se trata de hombres que van a la caza de sus presas sin importarles otra regla que la eficacia de su acción. También de mujeres cuya disponibilidad o ausencia está claramente planificada en función de conseguir el mejor precio por sus actuaciones.

En definitiva, el complejo sentimiento del amor sublime y de alta calidad ética y estética se traduce al constatar las reglas de su juego, sus artes, en un conjunto de oscuros o violentos manejos para conseguir objetivos. ¿Cuáles son esos objetivos para los dos sexos? Para los hombres, el objetivo principal es la relación sexual, el placer sexual; para las mujeres, no queda nada claro. Podría parecer que ese objetivo es también el placer sexual, ya que en líneas generales el placer se considera bueno y positivo para todos. Pero en lo que se refiere a las mujeres no parece ser éste el fin pretendido, ya que se aconseja tener sexualidad sin disfrute, e incluso ocultar esa falta de placer con un gran coste de fingimiento. Quedan otros objetivos «femeninos» que tienen muchas más posibilidades de ser ciertos. Por ejemplo, conseguir un buen marido, entendiendo por tal un marido con posición y valor social. En último término, y esto valdría para ambos sexos, el objetivo podría ser el propio amor, es decir tener un marido o una esposa o un amante a los que se pueda "amar», en el sentido más sublime del término. El problema en este caso sería cómo alcanzar un amor en el sentido sublime con las técnicas descritas, que nada tienen de moralmente elevado.

\section{BIBLIOGRAFÍA}

ANÓNImo (1996): Kamasutra (aforismos sobre el amor). Y Ananga Ranga (el teatro del amor), Tribuna, Barcelona.

ARCIPRESTE DE HitA (1995): Libro de buen amor, Castalia, Madrid.

ARundhati Roy (1998): El dios de las pequeñas cosas, Anagrama, Barcelona.

Fromm, E. (1967): El arte de amar, Paidós, Buenos Aires.

IBN HAZM DE CóRdoba (1997): El collar de la paloma, Alianza, Madrid.

Ovidio (1997): Amores, Arte de amar, Cátedra, Madrid.

SANGRAdOR, J. L. (1993): "Consideraciones psicosociales sobre el amor romántico», Psicotema, Oviedo, pp. 181-196. 


\begin{abstract}
This paper presents a sociological analysis about the concept of love and courtship technics and strategies in four classical texts: Kama Sutra, Ars Amandi, El collar de la paloma and the Libro de buen amor. The concept of love maintains a common significance along different historical periods. This common meaning consists of a high and positive feeling that transforms social relations as well as the personality of the lovers. On the other hand, courtship technics reinforce the rules of social structure, showing gender and social class inequality and also maintaining prejudiced stereotypes according to the values and cultures of their authors.
\end{abstract}

